\title{
Developing a simple, rapid method for identifying and monitoring jellyfish aggregations from the air
}

\author{
Jonathan D. R. Houghton ${ }^{1, *}$, Thomas K. Doyle ${ }^{2}$, John Davenport ${ }^{2}$, Graeme C. Hays ${ }^{1}$ \\ ${ }^{1}$ School of Biological Sciences, Institute of Environmental Sustainability, University of Wales Swansea, Singleton Park, \\ Swansea SA2 8PP, UK \\ ${ }^{2}$ Department of Zoology, Ecology and Plant Sciences, Lee Maltings, Prospect Row, Cork, Ireland
}

\begin{abstract}
Within the marine environment, aerial surveys have historically centred on apex predators, such as pinnipeds, cetaceans and sea birds. However, it is becoming increasingly apparent that the utility of this technique may also extend to subsurface species such as pre-spawning fish stocks and aggregations of jellyfish that occur close to the surface. In light of this, we tested the utility of aerial surveys to provide baseline data for 3 poorly understood scyphozoan jellyfish found throughout British and Irish waters: Rhizostoma octopus, Cyanea capillata and Chrysaora hysoscella. Our principal objectives were to develop a simple sampling protocol to identify and quantify surface aggregations, assess their consistency in space and time, and consider the overall applicability of this technique to the study of gelatinous zooplankton. This approach provided a general understanding of range and relative abundance for each target species, with greatest suitability to the study of $R$. octopus. For this species it was possible to identify and monitor extensive, temporally consistent and previously undocumented aggregations throughout the Irish Sea, an area spanning thousands of square kilometres. This finding has pronounced implications for ecologists and fisheries managers alike and, moreover, draws attention to the broad utility of aerial surveys for the study of gelatinous aggregations beyond the range of conventional ship-based techniques.
\end{abstract}

KEY WORDS: Aerial surveys $\cdot$ Gelatinous zooplankton $\cdot$ Jellyfish blooms $\cdot$ Scyphozoan $\cdot$ Rhizostoma octopus $\cdot$ Irish Sea

- Resale or republication not permitted without written consent of the publisher

\section{INTRODUCTION}

Aerial surveys have become an important technique for estimating the abundance and distribution of animals and population trends in a variety of habitats (Ancrenaz et al. 2005). The actual methods employed are as varied as the species observed, ranging from direct counts of the animals themselves (Marsh et al. 2005) to more integrated studies of changes in habitat (Boucher et al. 2004, Plante et al. 2004). The immediate advantage of aerial studies is the ability to gather data over a vast geographical range that would have been impossible using more traditional ground level techniques alone. For example, using an integrated approach, Ancrenaz et al. (2005) reported the distribution and size of orangutan populations throughout the entire state of Sabah, Malaysia, suggesting that up to
$60 \%$ of individuals were living outside protected areas. Such information is vital for biologists and policymakers alike, and often serves to facilitate more targeted studies at ground level.

Within the marine environment, aerial surveys have historically centred on apex predators, such as pinnipeds (Bengtson et al. 1990, Thompson et al. 2001) cetaceans (Sonntag et al. 1999, Forcada et al. 2004) and sea birds (Scheel \& Hough 1997, Gilchrist \& Mallory 2005). The underlying similarity of these species is their residence at the surface, or periodic requirement to return there to breathe. This enables the observer to detect the target not only close to the aircraft, but also some distance away, using distinctive surfacing characteristics. However, as detectability decreases with time spent away from the surface, the applicability of this approach to subsurface species might seem lim- 
ited. Nonetheless, there are numerous exceptions that overcome this fundamental limitation. For example, Royer et al. (2004) successfully identified aggregations of bluefin tuna Thunnus thynnus in relation to broadscale oceanographic features within the western Mediterranean, whilst Naumenko (2002) used aerial surveys to estimate the biomass of pre-spawning Pacific capelin Mallotus villosus socialis off the Kamchatka coast. Through technological advances such as the LIDAR system ('light detection and ranging'), it has also become possible to gather data from beneath the surface, enabling rapid surveys of the distribution and abundance of fish stocks in shallow coastal waters, and has provided some evidence that this approach might also reveal planktonic scattering layers (Churnside \& Wilson 2001, Brown et al. 2002, Churnside et al. 2003). Subsequently, the applicability of such techniques to fisheries biology has received much attention of recent years, enabling researchers to tackle ecological questions on an ever-increasing scale.

This use of aerial surveys as a starting point for more focused studies may, however, have utility beyond the scope of higher vertebrates. Indeed, recent studies have drawn attention to their potential for the study of scyphozoan jellyfish that form large aggregations near the surface (Purcell et al. 2000, Graham et al. 2003a). Logically, this is limited to relatively large and visibly detectable (i.e. non-transparent) species that aggregate, at least some of the time, in the top few metres of the water column. For example, Purcell et al. (2000) used visual observations from aircraft to estimate the number of Aurelia labiata aggregations found throughout Prince William Sound, Alaska. By conducting surveys over 3 consecutive years, these authors were able to detect marked interannual variations in the number of aggregations observed, from a minimum of 38 in 1997 to a maximum of 557 in 1996. More recently, Graham et al. (2003a), also working with large schyphozoan jellyfish, obtained photographic images (in slide format) of an extensive bloom of Phyllorhiza punctata that were digitised for image-analysis. When possible, discrete jellyfish were counted, however images of the most concentrated aggregations often did not produce discrete data because the medusae appeared overlapped. For these images, the authors calculated percent coverage of jellyfish pixels in the images and applied a conversion of pixels jellyfish ${ }^{-1}$ determined from the discrete jellyfish.

The implications of such techniques are great, as gelatinous zooplankton have gained notoriety as potential competitors of commercially important fishes since the arrival of the north American ctenophore Mnemiopsis leidyi in the Black Sea in the early 1980s (Kideys 1994, Shiganova 1998, Shiganova \& Bulgakova 2000). The fundamental concern over increasing gelatinous communities is that energy previously directed towards fishes may become diverted (Mills 1995, 2001, Purcell \& Arai 2001). As jellyfish and larval fishes often feed on the same kinds of prey, there is a corresponding need to monitor changes in jellyfish abundance and distribution for potential ecological problems to be identified (Mills 2001). Despite this concern, there is still surprisingly little known about fundamental aspects of the life history of many jellyfish species (Buecher et al. 2001). In many cases even basic parameters such as range, demography and trophic importance remain poorly documented. However, for jellyfish species that are large and occur near the surface, it is possible to observe blooms from low-flying aircraft, allowing fairly large areas to be rapidly surveyed (Hays et al. 2003). With this aim, we tested the utility of aerial surveys to provide baseline data for 3 seasonally abundant, yet poorly understood, scyphozoan jellyfish found throughout British and Irish waters during the summer months. Our principal objectives were to assess the applicability of this approach to each species, identify and quantify surface aggregations, and assess their consistency in space and time. For this we required a technique applicable over broad areas spanning thousands of square kilometres yet providing detailed information on the aggregations themselves. Although previous studies have touched upon these issues (Purcell et al. 2000, Graham et al. 2003a), few have focused in detail on the methods employed per se. Our study aimed at highlighting the advantages and disadvantages of this potentially important technique for the study of gelatinous zooplankton.

\section{MATERIALS AND METHODS}

Survey area and design. Aerial surveys were conducted throughout the southern Irish Sea from July to October during 2003 and 2004. We tested the suitability of 3 large scyphozoan species for this approach: the barrel jellyfish Rhizostoma octopus, the lion's mane Cyanea capillata and the compass jellyfish Chrysaora hysoscella (henceforth referred to as Rhizostoma, Cyanea and Chrysaora respectively). These species were deemed suitable for the following reasons. Firstly, they are all large, with Rhizostoma and Cyanea displaying bell diameters up to and in excess of $1 \mathrm{~m}$; whereas Chryosaora can be easily recognized by its extensive trailing oral arms, themselves often $>1 \mathrm{~m}$ in length. Secondly, each species is distinctively coloured and not transparent (as is often the misconception for all jellyfish). Rhizostoma appears as milky white, Cyanea as deep brown/red, with Chrysaora a combination of red/brown bell with lighter-brown oral arms. Their visibility to the naked eye was quite remarkable, 


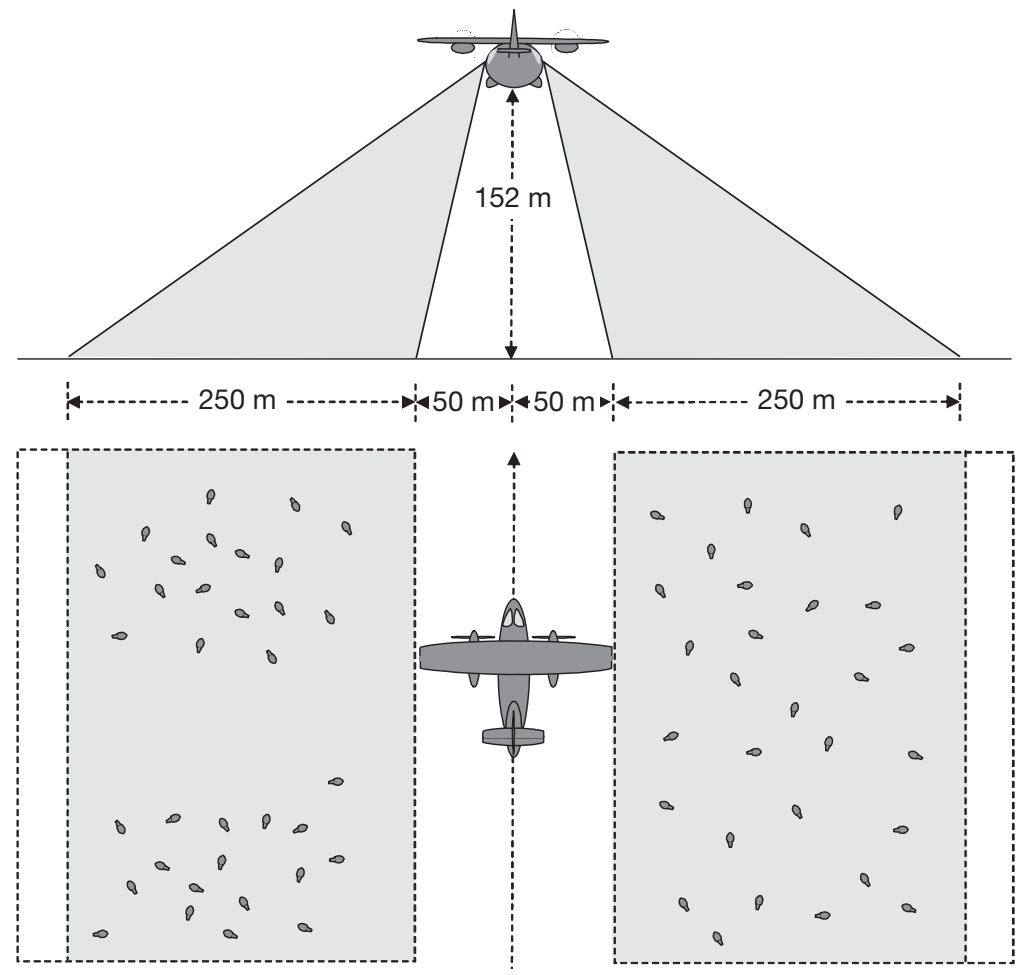
at speed of $185 \mathrm{~km} \mathrm{~h}^{-1}$. Field of view was limited to bands of $250 \mathrm{~m}$ on either side of aircraft, allowing observers ( 1 each side) to assess an area of $\sim 7700 \mathrm{~m}^{2}$ during each 5 min survey period
Fig. 1. Aerial survey pattern. Surveys were conducted from height of $152 \mathrm{~m}$

periods with a break of at least $1 \mathrm{~h}$ to avoid observer fatigue (e.g. Bodkin \& Udevitz 1999, Rugh et al. 2002). Observations were restricted to $250 \mathrm{~m}$ each side of the aircraft, beyond which distance estimates of sub-surface targets such as jellyfish became impractical. This area was determined using an inclinometer, with observations limited to a range between $72^{\circ}$ (50 $\mathrm{m}$ from aircraft) and $27^{\circ}$ (300 m from aircraft) from the horizontal (Fig. 1).

The numbers of jellyfish observed were tallied into 5 min time intervals using the following categories for each observer: $<10,10$ to 50,51 to 100,101 to $500,>500$. For each $5 \mathrm{~min}$ interval, the totals of both observers were combined to give an estimate of abundance over an area of approximately $7700 \mathrm{~m}^{2}$ (Fig. 1). Depth-ofview was taken to be a maximum of $1 \mathrm{~m}$, although this factor did not directly affect observations as jellyfish were sighted either at, or directly below the surface.

The survey design was based upon 2 basic principles. Firstly, to conduct transects across the Irish Sea encompassing both coastal (defined as within $7 \mathrm{~km}$ of the shore) and open-water areas (Fig. 2). This was to test the proposal of Russell (1970) that jellyfish blooms for all British schyin that it was possible from the survey altitude (a mere $152 \mathrm{~m}$ ) to confidently identify the species to such a degree that it was even possible to observe the pulsations of the bell. Subsequently, it was not felt necessary to carry out any form of photographic or video validation. Confirmation was simply achieved by comparing the species observed in coastal locations with those stranded on proximate shores. Furthermore, the scope for error in identification is minimal in the Irish Sea, as only 5 species of schyphozoan jellyfish are present. The only possible scope for error would be in discriminating Cyanea capillata and its close relative $C$. lamarckii: this was achieved on the basis of size and colour, the latter species being smaller (bell diameter up to $\sim 30 \mathrm{~cm}$ ) and blue in colour. Validation was achieved by supporting beach surveys (see subsection 'Verifying aerial observations' below). We restricted our study to the 3 large species; smaller more translucent species such as Aurelia aurita were excluded from the study.

Estimates of jellyfish abundance were made from an altitude of $152 \mathrm{~m}$ at a constant speed of 100 knots (185 $\mathrm{km} \mathrm{h}^{-1}$ ) by 2 observers, 1 on each side of the plane. Following established guidelines, individual survey days were broken down into two $90 \mathrm{~min}$ phomedusae other than Pelagia noctiluca are coastal in nature. Secondly, once jellyfish blooms were identified, repeated coastal surveys based on line transects $2 \mathrm{~km}$ apart were carried out over a time scale of months to assess the consistency of these blooms in space and time (Fig. 2b).

Accounting for glare and operator error. For aerial surveys conducted at sea, glare constitutes a significant problem often rendering observations from one side of the aircraft impractical at any given time. To provide empirical data on glare, estimates were made by each observer using a system of 'octares' every 5 min to correspond with the estimates of jellyfish abundance. For this, the field of vision from each side of the aircraft was visually divided into 8 sections. The number of sections obscured by glare was subsequently noted, providing a simple, yet standardised, approach to this problem. By recording these data, we were subsequently able to make a robust assessment of operator error (i.e. inconsistencies in abundance estimations between observers). Data collected under ideal conditions (i.e. 0 glare from both sides of the aircraft) were compared to test for similarities in recorded abundances of Rhizostoma. Using this baseline, estimates of Rhizostoma abundance were compared conditions when 0 octares 

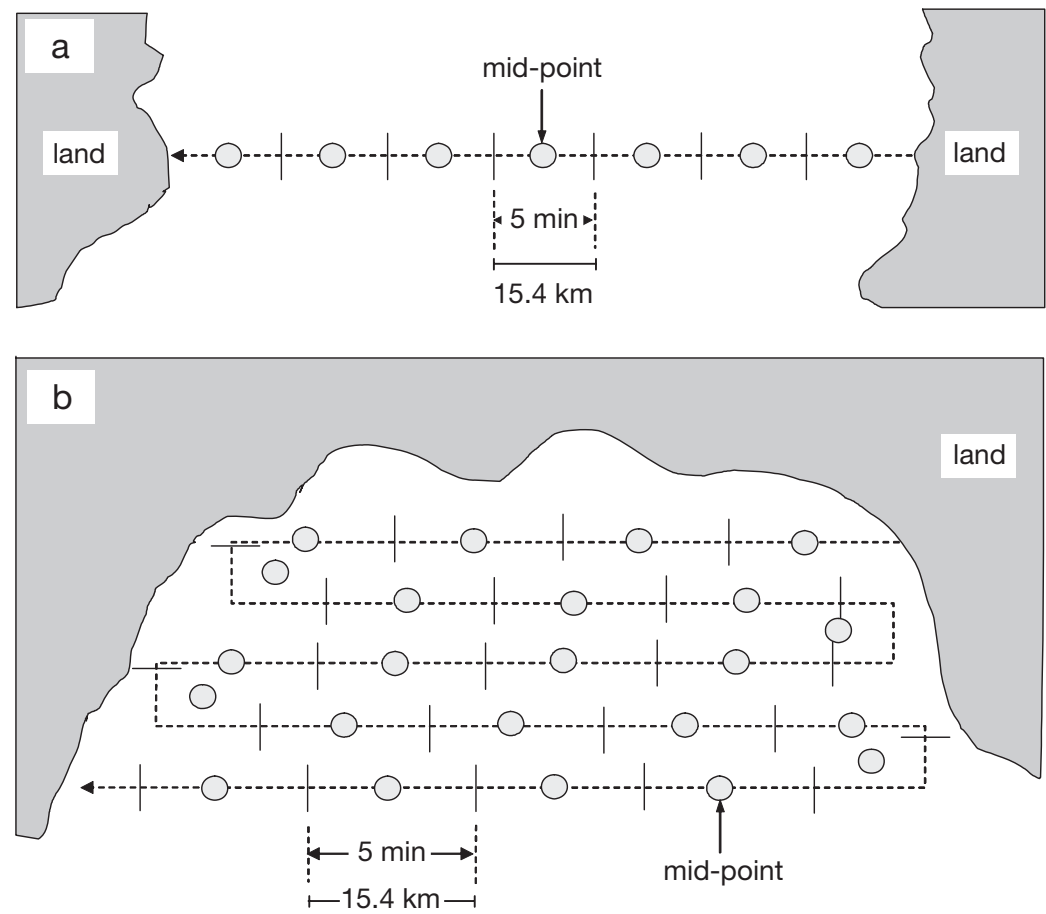

Fig. 2. Determination of mid-point locations used in distribution plots for (a) open-sea transects, and (b) during repeated coastal survey patterns to assess consistency of blooms in space and time. Individual line transects were conducted $2 \mathrm{~km}$ apart, giving $25 \%$ coverage of each large embayment events to validate both the species identification, and as a proxy for localised abundance. For example, if large numbers of jellyfish strand repeatedly in a given area yet only small numbers are recorded from the air, the observer at least gains an intuitive feel that aerial estimates may be an underestimation of species abundance. Beach surveys constituted double line-transects along the water's edge and the high-tide mark to record the number of stranded jellyfish. These were conducted at, or as close to low water as possible to maximise the chance of encountering stranded jellyfish (Houghton \& Doyle pers. obs.). Identification was conducted to species level using taxonomic features outlined by Russell (1970).

Logically, care must be taken in expecting aerial estimates of abundance to be correlated with estimates derived from beach strandings. Because the latter is dependent upon a large number of factors such as localised current regimes and prevailing winds, it is entirely possible to obtain high densities at sea and low numbers of strandings. This problem has been previously highlighted by the

were obscured from one side of the aircraft and 1 to 6 octares were obscured from the other. Using the 0 octares data as the baseline, it was possible to derive correction factors to account for the numbers of jellyfish that were not observed as a function of glare (see Fig. 3 \& Table 1).

Sea state. For studies of surfacing megafauna such as cetaceans or pinnipeds, sea state is an important factor determining the detectability of target species. For subsurface species such as jellyfish, this problem is further compounded as the observer is required to look directly down into the water column. To minimise the influence of this factor, aerial surveys were restricted to times when surface winds were less than Force 4 on the Beaufort scale. However, on occasion, sea state became elevated during the survey, allowing an opportunity to assess how this factor might affect numerical estimates of jellyfish seen from the air.

Verifying aerial observations. Once coastal aggregations of jellyfish had been identified from the air, beach surveys were conducted to collect data on stranding
Table 1. Effect of glare on observed jellyfish abundance. Data (recorded simultaneously) shown for both sides of aircraft: side with no glare $(x)_{i}$ and side hindered by varying states of glare $(y)$. Glare values $=$ number of octares obscured, ranging from no glare (0 octares) to $75 \%$ of field obscured (6 octares)

\begin{tabular}{|c|c|c|c|}
\hline $\begin{array}{l}\text { Unobscured } \\
\text { side }(x)\end{array}$ & $\begin{array}{l}\text { Obscured } \\
\text { side }(y)\end{array}$ & Regression data & $\begin{array}{l}\text { Linear regression } \\
\text { equation }\end{array}$ \\
\hline 0 & 0 & $\begin{array}{l}F_{1,35}=2793.01 \\
\mathrm{r}^{2}=0.98, \mathrm{p}<0.05\end{array}$ & $y=0.985 x+4.9544$ \\
\hline 0 & 1 & $\begin{array}{l}F_{1,12}=2231.00 \\
\mathrm{r}^{2}=0.99, \mathrm{p}<0.05\end{array}$ & $y=1.0023 x+1.704$ \\
\hline 0 & 2 & $\begin{array}{l}F_{1,16}=47.70 \\
\mathrm{r}^{2}=0.76, \mathrm{p}<0.05\end{array}$ & $y=0.7039 x+20.895$ \\
\hline 0 & 3 & $\begin{array}{l}F_{1,8}=62.21 \\
\mathrm{r}^{2}=0.89, \mathrm{p}<0.05\end{array}$ & $y=0.6589 x+21.928$ \\
\hline 0 & 4 & $\begin{array}{l}F_{1,22}=121.83 \\
\mathrm{r}^{2}=0.89, \mathrm{p}<0.05\end{array}$ & $y=0.7013 x+2.2858$ \\
\hline 0 & 5 & $\begin{array}{l}F_{1,21}=118.64 \\
\mathrm{r}^{2}=0.85, \mathrm{p}<0.05\end{array}$ & $y=0.7138 x+1.4411$ \\
\hline 0 & 6 & $\begin{array}{l}F_{1,19}=35.32 \\
\mathrm{r}^{2}=0.76, \mathrm{p}<0.05\end{array}$ & $y=0.4432 x+6.7981$ \\
\hline
\end{tabular}




\section{RESULTS}

\section{Accounting for glare and operator error}

Fig. 3 shows the differences in recorded abundance with varying degrees of glare. The data represent all 5 min observation periods when Rhizostoma were pre-
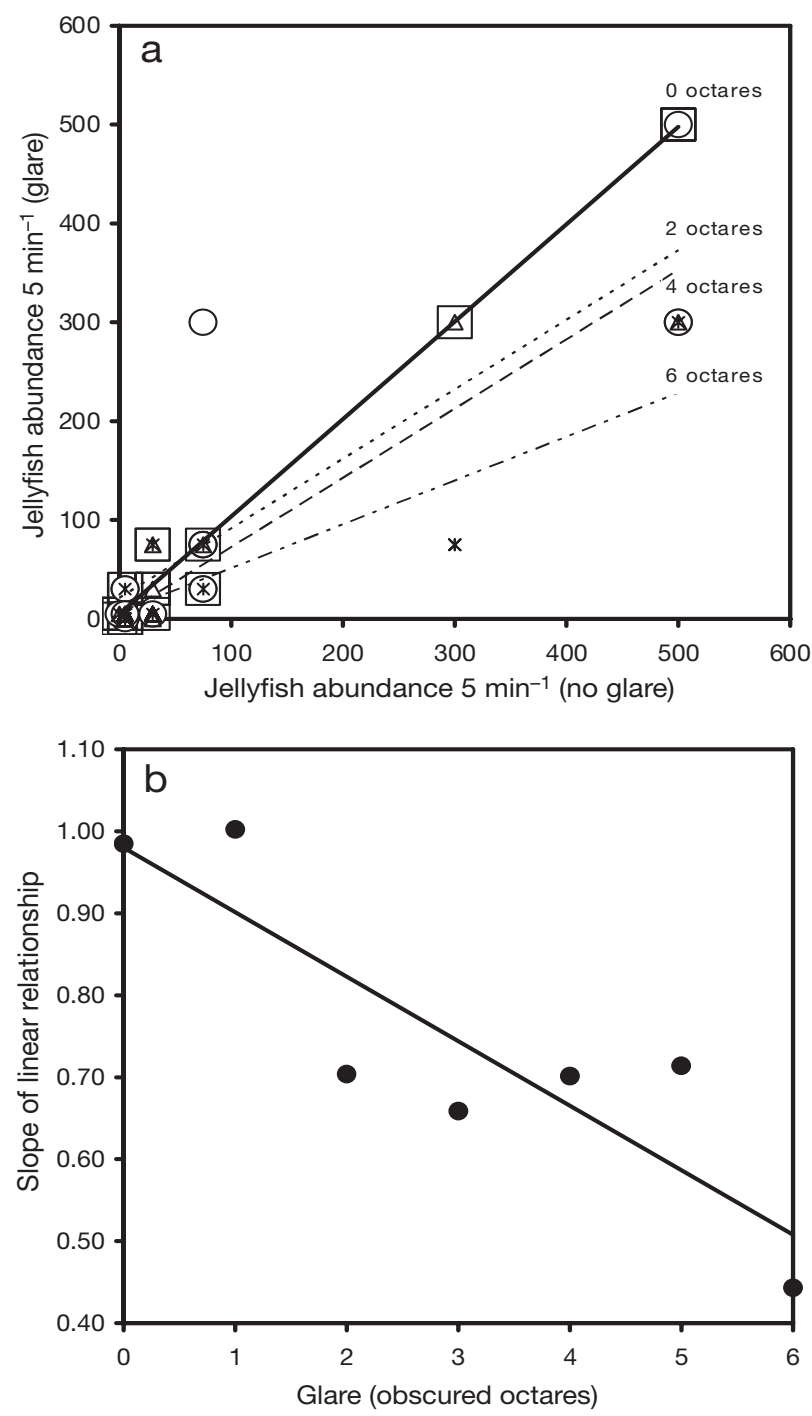

Fig. 3. (a) Variability in abundance estimates from opposite sides of aircraft as a function of glare (number of octares obscured, i.e. ' 4 octares' indicates that 4 of the 8 octares in the field of vision $(50 \%)$ were rendered useless to the observer by surface glare). Estimated abundances under varying degrees of glare ( $y$-axis) are shown as a function of estimations made from side of aircraft where view was unobscured ( $\mathrm{X}$-axis), and reveal that, as glare increased, estimates of jellyfish abundance decreased in a linear fashion enabling correction factors to be determined. Data are for following scenarios: $(\mathrm{O}) 0$ octares vs. 0 octares $(\mathrm{n}=36) ;(\square) 0$ octares vs. 2 octares $(\mathrm{n}=17)$; $(\Delta) 0$ octares vs. 4 octares $(n=23) ;(*) 0$ octares vs. 6 octares $(\mathrm{n}=20)$. (b) Relationship between slope of linear equations shown in (a) and in Table 1 sent in both years (see Table 1). Effect on detectability was assessed by firstly comparing the observed abundances on both sides of the aircraft under ideal conditions (i.e. 0 glare on both sides of the aircraft). This enabled us to empirically assess the possible influence of inter-operator error, and gain an insight into the structure of the blooms themselves. This revealed a marked consistency between observers and showed that when aggregations of jellyfish were observed from one side of the aircraft, similar abundances were also recorded by the observer on the opposite side (Fig. 3 \& Table 1). Given this baseline, we were able to assess how abundance estimates varied between observers under varying degrees of glare, which allowed us to correct for this factor in the final analysis. For example, under conditions of 0 glare, observers flying over a major aggregation might both record jellyfish numbers in excess of 500 within a 5 min period. If significant glare had restricted observations on one side of the aircraft, these results might change, with 500 jellyfish recorded from the glare-free side of the plane, and only 75 recorded from the other. Using the linear relationships in Fig. 3, the data from the obscured side could be corrected to give a more representative estimate of abundance. Correspondingly, all data presented have been corrected for glare. The manner in which different glare conditions affect estimates of abundance is shown in Fig. 3b, which reveals a significant negative relationship between the slope of the linear equations (outlined in Table 1 and Fig. 3a) and increasing glare $\left(F_{1,5}=16.31, \mathrm{r}^{2}=0.77, \mathrm{p}<0.05\right)$, confirming that estimates of abundance decrease as a function of increasing glare.

\section{Survey coverage}

A total of 11951 linear kilometres of aerial surveying was conducted from July to October 2003 and 2004 (2003: 6068km; 2004: 5883km), encompassing the length and breadth of the southern Irish Sea. This represented a total of 394 estimates of jellyfish abundance (i.e. mid-points of each 5 min survey period) during 2003 and 383 in 2004 (Fig. 4).

\section{Spatial and temporal patterns of jellyfish aggregations}

\section{Rhizostoma octopus}

Although individual Rhizostoma were seen during open-sea transects, major aggregations were found only in coastal areas. More specifically, 3 'core areas' were identified in which jellyfish were repeatedly observed in high densities (i.e. >800 individuals ob- 

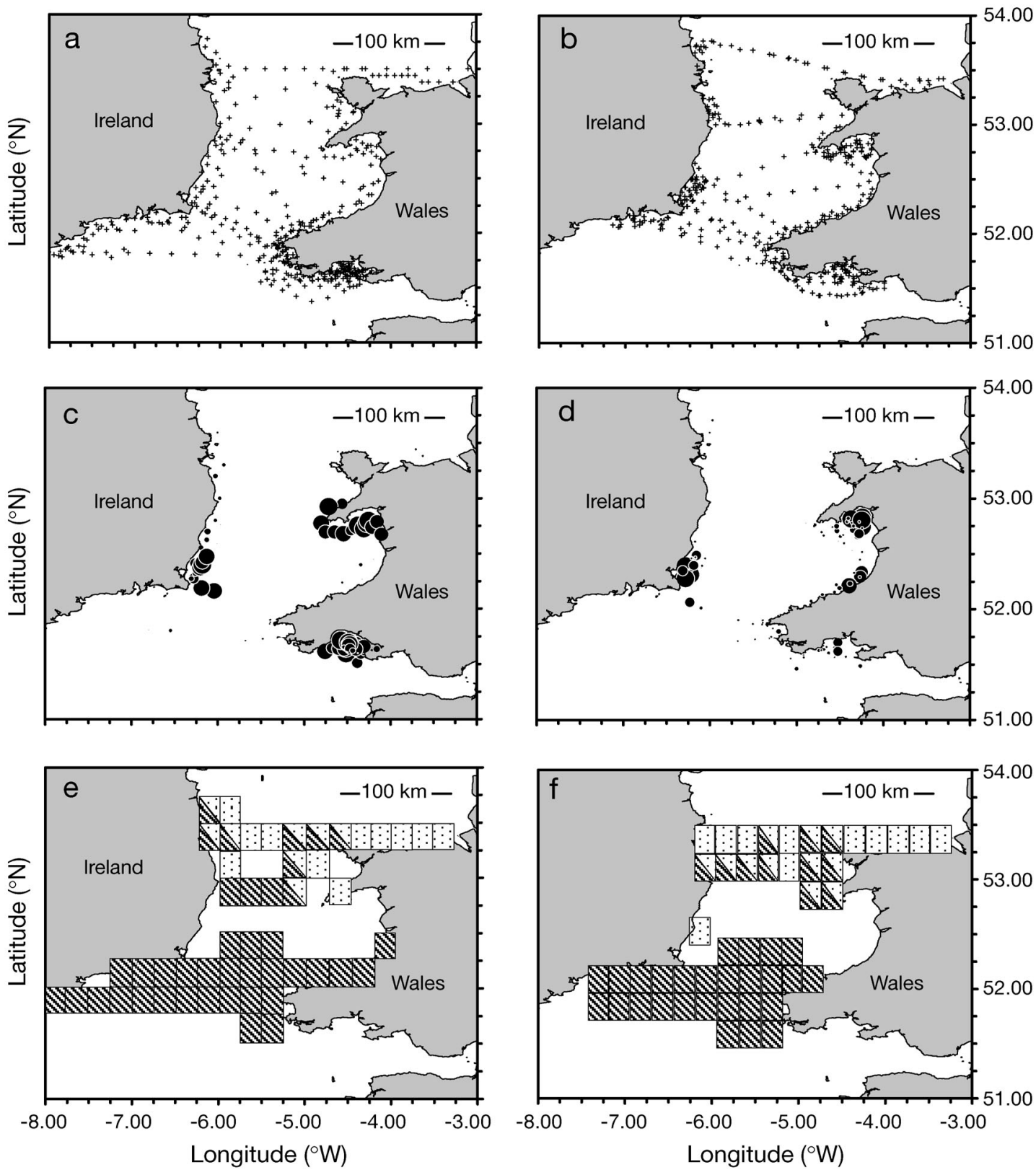

Fig. 4. Rhizostma octopus. (a,b) Location (+) of each 5 min mid-point for 2003 and 2004, respectively. (c,d) Combined abundance and distribution in 2003 and 2004, respectively: scale ranges from abundances of $>1000$ ind. 5 min $^{-1}$ (i.e. per $\sim 7700 \mathrm{~m}^{2}$ ) (largest circles) down to abundances of $<10$ ind. $5 \mathrm{~min}^{-1}$ (smallest circles). Presence and absence data are shown for Chryosaora (diagonal hashed lines) and Cyanea (dotted) during 2003 (e) and 2004 (f). Data are shown for each $0.25^{\circ}$ latitude $\times 0.25^{\circ}$ longitude grid square. Where species are absent no data is shown. Difference in Chryosaora distribution between two years largely reflects sampling effort with 2004 characterised by more repetitive open-water transects through the central study area (see Fig. 4a,b).

served within a 5 min survey period): Carmarthen Bay in South Wales, Tremadoc Bay in North Wales, and Rosslare on the SE coast of Ireland (Fig. 4). These 'jellyfish hotspots' represented an area of $4615 \mathrm{~km}^{2}$ out of a total survey area of $60114 \mathrm{~km}^{2}(7.7 \%)$.

Despite a consistent presence within these core areas, the blooms on occasion expanded to cover sub- stantial areas on both sides of the Irish Sea. This was exemplified during September 2003, when high densities of Rhizostoma extended over $100 \mathrm{~km}$ northwards from Rosslare. A second example of such expansive events occurred during June 2004 when Rhizostoma, normally observed in Tremadoc Bay alone, stretched southwards along the entire length of Cardigan Bay 

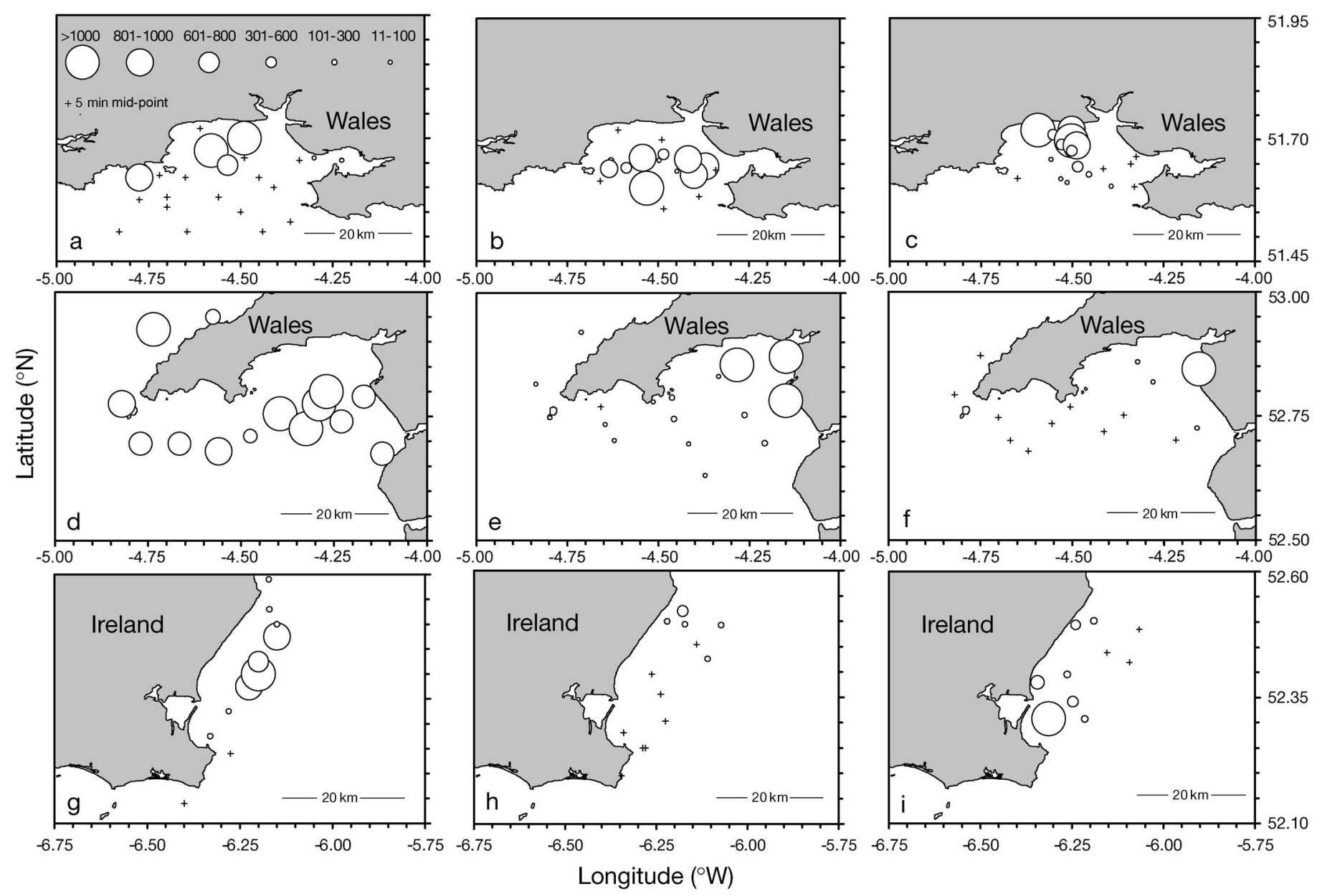

Fig. 5. Rhizostoma octopus. Spatial patterns of blooms within and between surveys and years. Estimates of abundance for each 5 min mid-point are shown: (O) individuals present; $(+)$ none observed. Data are shown for each of the 3 hotspots identified, indicating area covered by surface aggregations. (a to c) Carmarthen Bay on (a) 05/08/03, (b) 25/08/03, (c) 12/09/03; (d to f) Tremadoc

Bay on (d) 19/09/03, (e) 06/08/04, (f) 25/06/04; Rosslare on (g) 18/09/03, (h) 15/08/04, (i) 28/08/04). Scale is ind. 5 min ${ }^{-1}$

towards South Wales (Fig. 4d). Interestingly, as the summer progressed, these expansive blooms appeared to contract and, by late July, jellyfish were again found only in the core area of Tremadoc Bay.

Repeated surveys of the 3 core areas further revealed that the blooms moved to different locations throughout the bays themselves. This constituted either the movement of a defined bloom between different areas of the bay, or the concentration or dispersal of the bloom itself, such that the area covered varied greatly (Fig. 5).

\section{Cyanea capillata and Chrysaora hysoscella}

No large aggregations of either species were identified during open-sea transects or within coastal embayments. When present, the numbers of individuals observed were typically low compared with Rhizostoma (Cyanea: $\max =80$ ind. $5 \mathrm{~min}^{-1}$, mean $=23.6$; $\mathrm{SD}=19.3 ;$ Chrysaora: $\max =35$ ind. $5 \mathrm{~min}^{-1}$, mean $=$ 12.3 ind. $5 \mathrm{~min}^{-1} ; \mathrm{SD}=11.11$ ). Subsequently, it proved difficult to assess how these 2 species varied over space and time. However, broad-scale, generalised statements could be made. For example, on a spatial scale, Cyanea displayed a distinct northern skew with individuals almost exclusively seen during the most northerly transects (both coastal and open sea). Conversely, Chrysaora was more cosmopolitan in its range, with low densities recorded intermittently throughout the entire survey area. Temporally, both Cyanea and Chrysaora were mainly observed during July and August, with individuals rarely being observed during the late autumnal months. This was in marked contrast to Rhizostoma, which was observed throughout the entire survey period. 

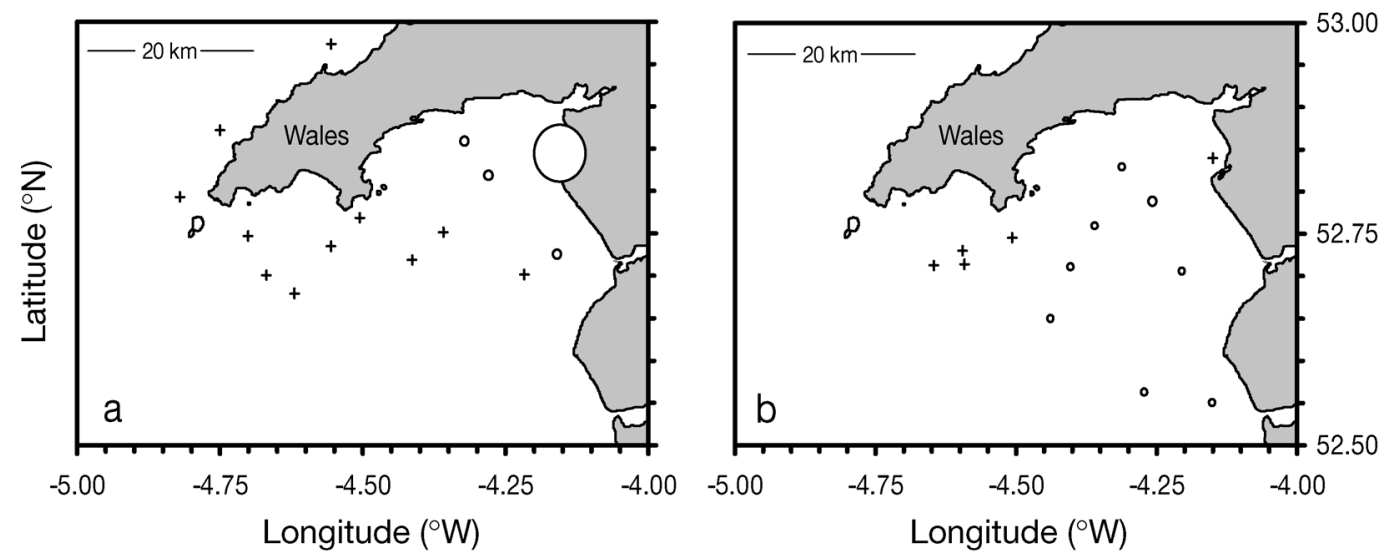

Fig. 6. Rhizostoma octopus. (a) Abundance in Tremadoc Bay on 21/08/04 with extremely calm sea state (Beaufort Force 1), revealing large aggregation of jellyfish (>1000 ind. $5 \mathrm{~min}^{-1}$ : large circle) at mouth of an estuary; (b) $5 \mathrm{~d}$ later, when sea state was Beaufort Force 3 to 4 , aggregation was no longer visible. (O) individuals present; (+) none observed

Influence of sea state

Sea state had a large effect on the detectability of jellyfish from the air. This was most clearly demonstrated in repeated surveys of Rhizostoma core areas as shown for Tremadoc Bay in Fig. 6. Fig. 6a shows a survey conducted on 21 August 2004, a sunny day with an extremely calm sea (Beaufort Scale 1 to 2 ). This survey revealed a large jellyfish aggregation close to the shore that was not evident in a subsequent survey conducted only $5 \mathrm{~d}$ later when the sea state had risen slightly and conditions were overcast (Beaufort Scale 3 to 4 ) (Fig. 6b). Given the consistency of these blooms within the bays, and observations of increased abundance later in the season, it seems reasonable to suggest that the differences between these 2 surveys were associated with sea state. Nonetheless, insufficient data on the response of jellyfish to increases or decreases in sea state prevented the development of correction factors at this stage. This will hopefully form the basis of further studies to allow data collected during nonoptimal conditions to be interpreted effectively.

\section{Verifying aerial observations}

In each instance, beach surveys confirmed that observations made from the air were consistent with the species stranding in corresponding coastal areas. For example, if the aerial survey identified the occurrence of Rhizostoma, Cyanea and/or Chrysaora in the coastal area, they were always found adrift on adjacent beaches. This allowed confidence in our ability to accurately identify species from the air, and was used as validation for both coastal and open-water transects.

Fig. 7a shows the location of beaches used for spe- cies-validation. For Wales and Ireland combined, a total of 1149 individual beach surveys were conducted between June 2003 to June 2005, with > 29000 jellyfish identified to species level. For Rhizostoma, high numbers of individuals were found stranded in the 3 bays during 2003 and 2004 (i.e. $>50$ ind. $100 \mathrm{~m}^{-1}$ in individual stranding events) which, incidentally, reflected the high numbers observed at sea. The converse was true for Chrysaora which showed low densities at sea and low-density stranding events (typically $<1$ ind. $100 \mathrm{~m}^{-1}$ ). The situation was different for Cyanea, which exhibited high-density stranding events (>50 ind. $100 \mathrm{~m}^{-1}$ ) with only low abundances observed from the air. For Cyanea it is highly probable, therefore, that aerial surveys significantly underestimate the number of jellyfish present within the water column (Fig. 7b). Although it is possible that Cyanea stranding events occur through the concentration of widely dispersed individuals by localised current regimes, it is also feasible that the vertical distribution of Cyanea may be such that the numbers of animals observed at the surface may be a gross underestimation of the numbers beneath.

Lastly, as an indirect measure of seasonality (or at least the seasonality of stranding events), the date and magnitude of stranding events revealed that Cyanea and Chrysaora were typically abundant during the summer months, whilst Rhizostoma stranded on the beach continually throughout the year (Fig. 7c).

\section{DISCUSSION}

Once thought to be an insignificant component of marine ecosystems, gelatinous zooplankton is now viewed as an integral link within pelagic and coastal 

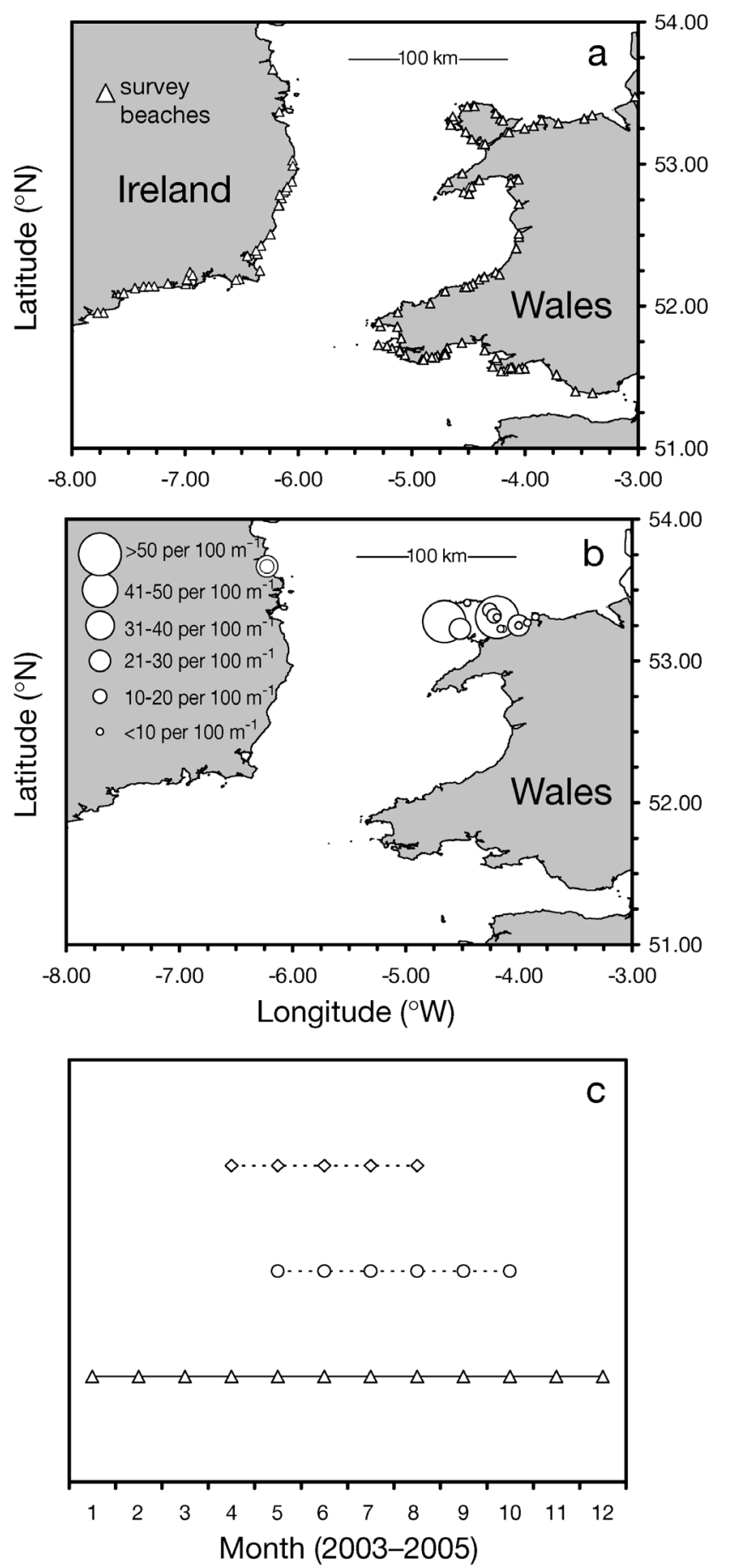

Fig. 7. (a) Survey beaches used for validation along Welsh (n $=88)$ and Irish $(\mathrm{n}=67)$ coasts during 2003 and 2004; (b) extensive stranding events of Cyanea capillata during 2004 that were in excess of any aggregations recorded during air survey; (c) indirect and rudimentary indicator of seasonality determined from stranding events (Wales and Ireland combined) for the 3 target species: Rhizostoma octopus $(\Delta)$, Chrysaora hycosella ( $\diamond)$ and Cyanea capillata (O), suggesting that presence of $R$. octopus within water column may extend beyond typical seasonality of the other species (positions of symbols indicate dates of individual stranding events) food webs (e.g. Purcell \& Arai 2001, Arai 2005). Indeed, recent studies have shown that large jellyfish such as the schyphomedusae represent a conspicuous component of the plankton, especially during the productive summer months (Brodeur et al. 2002). Nonetheless, ecological studies involving such species have been limited by an inability to measure the abundance and distribution patterns of these highly aggregated animals at local scales (Graham et al. 2003b). Significant advances have recently been made to address this gap in our knowledge through in situ video-recorders (Graham et al. 2003b), remotely-operated vehicles (Dennis 2003, Sparks et al. 2005) and acoustics (Brierley et al. 2004). The latter has benefited from the application of multi-frequency techniques that, in some instances, enable jellyfish species to be identified (Brierley et al. 2005) and discriminated from pelagic fishes. Through this, it is now possible to separate echoes from commercially important fishes and jellyfish, moving us closer to species-specific acoustic estimations of jellyfish abundance (Brierley et al. 2005). Such stock assessments typically seek to determine the abundance of a particular species in a particular area rather than which area has the highest abundance. Nonetheless, the ability to conduct such in-depth surveys is fundamentally underpinned by a requirement to know where to look in the first instance; the logistical and economic constraints of ship-based studies renders these inappropriate for speculative exploratory investigations.

The broad utility of aerial surveys to identify and monitor jellyfish aggregations has been previously demonstrated via direct counts of jellyfish aggregations in Prince William Sound (Purcell et al. 2000) and detailed digital image-analysis of invasive species in the Gulf of Mexico (Graham et al. 2003a). Nevertheless, the underlying similarity was the use of the technique to locate and assess the abundance of jellyfish and facilitate more detailed studies once target areas had been identified. The simple sampling protocol described in the present study further demonstrates the potential of this approach for rapid assessment of jellyfish aggregations, particularly in the case of Rhizostoma. For example, despite the extraordinarily high abundances of this species throughout the study, it has only previously been reported sporadically throughout British and Irish waters (Russell 1970), with details of its distribution, seasonality and abundance sadly lacking. By identifying both spatial and temporal patterns of abundance we are now able to start piecing together previous data alluding to the periodic prevalence of this species in coastal environments. For example, O'Connor \& McGrath (1978) reported extraordinarily high abundances around the entire coast of Ireland during 1976, and in 1992, the 
Hunterston Nuclear Power Station (Clyde Sea, Scotland) had to be shut down because a Rhizostoma bloom blocked its cooling system (J. Davenport pers. obs.). More interestingly, in other areas around the $\mathrm{UK}$, the species seems to be very rare. In an analysis of $>2030$ fish trawls made in the North Sea between 1971 and 1986, only 1 specimen of Rhizostoma was recorded (Hay et al. 1990). Set against this backdrop of patchy, unrelated findings, our aerial surveys provided an invaluable insight into the broad-scale distribution of the species, beyond the scope of conventional sampling techniques.

In terms of intra-annual variability, aerial surveys are not necessarily applicable to continuous monitoring of jellyfish population dynamics per se, yet repeated surveys revealed that, on occasion, the range of Rhizostoma may expand dramatically. In the southern Irish Sea, 3 core areas were identified where individuals were recorded in high abundance; Carmarthen and Tremadoc Bays in Wales and Rosslare on the SE coast of Ireland. On 2 occasions, however, large numbers were observed along the entire west coast of Wales and several hundred kilometres of the east coast of Ireland. The nature of such events is not explored within this study; rather, our aim was to draw attention to the potential of this approach to identify both subtle and dramatic shifts in species range over time. It is possible that such expansive events are a periodic feature of Rhizostoma aggregations, perhaps explaining the extraordinarily high abundances described by O'Connor \& McGrath (1978). Given the current concern surrounding jellyfish as trophic conduits for larval fishes, aerial survey may prove an invaluable tool, with the ability to assess quickly when such species move into an area where they may overlap with economically important fisheries.

In terms of interannual variability in jellyfish blooms, previous studies have highlighted how abundance may differ dramatically between years. For example, in their study of Aurelia labiata in Prince William Sound, Purcell et al. (2000) conducted aerial surveys from May through to August in 3 consecutive years, revealing marked differences in the number of aggregations observed, from a minimum of 38 in 1997 to a maximum of 557 in 1996. Similar findings are reported herein regarding the prevalence of Rhizostoma throughout Carmarthen Bay. Although the species was present in both years, the numbers observed during 2003 were in excess of those the following year when modest aggregations were recorded throughout August (Fig. 4c,d).

Information on the distribution and abundance of medusae derived from surface observations is, however, subject to a number of criticisms (Sparks et al. 2001). Foremost, observations are dependent upon sea state and visibility, reflect observer bias, and are also influenced by diel vertical migration (DVM) (Sparks et al. 2001). Indeed in survey design, the potential affect of sea state is a factor that must be taken into consideration from the outset. Our data reveal that increased sea state (i.e. rougher conditions) may influence the recorded abundance and distribution of jellyfish in 2 ways. For Rhizostoma, this may be initially through decreased detectability, with the observer's eye drawn away from potential targets by having to constantly assess and disregard the white caps of waves. Secondly, there may be a biological response of the target species itself to conditions at the sea surface. For example, our data suggest that Rhizostoma moved deeper in the water column when conditions became rough and overcast, yet aggregated at the surface in very high numbers on calm, sunny days. The exact biological function of these vertical movements remains unclear, although similar findings have been reported from the Irish Sea whereby Rhizostoma appeared to sensitive to the noise and vibration of an approaching boat and sank into deeper water (Nagabhushanam 1959). Anecdotally, Russell (1970) also reported that during crossings from Liverpool to Douglas, Isle of Man (Irish Sea), patches of water, some 40 to $50 \mathrm{~km}$ in area, contained Rhizostoma of 1 ind. $\mathrm{m}^{-2}$, ranging from tennis-ball size to almost $1 \mathrm{~m}$ diameter. In calm weather many of these were visible at the surface at a distance of up to $50 \mathrm{~m}$, with larger individuals sometimes visible at a distance of up to $100 \mathrm{~m}$. However, by the time the ship reached them, they had sunk below the surface. Presumably on feeling the vibrations of the ship's engine they ceased pulsating and sank passively (Russell 1970) which (arguably) may replicate the effect of a rough sea state. This provides some degree of confidence that the vast coastal aggregations observed in the present study were not merely a function of restricted depth within the bays forcing the jellyfish to the surface, but also a response to warm, calm weather. Indeed, when considering the evidence for a coastal bias in the distribution of Rhizostoma, this is an important factor to take into account as it partially alleviates the concern that low numbers in the open-sea transects are merely a function of increased depth allowing individuals to reside at more optimal depths.

Temporally, therefore, sea state imposes constraints upon the observer, whereby abundance data may only be obtained during periods of calm weather. Logically, this centres on the summer months, when medusae are abundant in the water column and increased sea state does not hinder observations. Nonetheless, for species such as Rhizostoma that appear to be almost present within the water column the whole year round, it may be feasible to extend surveys into periods of good weather during the spring and autumn months. 
In terms of suitability for survey, of the 3 target species only aggregations of Rhizostoma were clearly identified. For Cyanea at least, it is likely that vertical distribution throughout the water column significantly affected the numbers of individuals observed from the air. Chrysaora may simply not aggregate at the surface. An insight into this is provided by Brodeur et al. (2002) in their study of scyhphomedusae in the Bering Sea in which integrated vertical distributions (day and night) of 5 dominant species were determined using remotely operated vehicles. This revealed a peak abundance of Cyanea capillata at depths of 30 to $35 \mathrm{~m}$, with a close relative of Chrysaora hysoscella ( $C$. melanaster) found throughout the water column at peak densities between 15 and $40 \mathrm{~m}$. For both species, surface abundance was either negligible, or grossly underrepresentative of their biomass at greater depths, leading the authors to suggest that surface plankton tows (and consequently aerial surveys) would significantly underestimate the abundance of these species. Acoustic evidence of DVM in C. hysoscella was presented by Brierley et al. (2001) whereby the respective sound scattering layer at $25 \mathrm{~m}$ was clearly visible during the day, but less distinct at night, probably as individuals migrated upwards in the water column, returning to depth the following day (Sparks et al. 2001). These observations provide compelling evidence as to why the numbers of stranded individuals found along the shore in the present study were significantly greater than those observed from the air. However, despite this obvious limitation, we were still able to obtain qualitative data on the areas of species occurrence (by 'qualitative' we mean the ability to detect the presence or absence of a species at the surface, in a given area at a given time). In essence this is quite different from the situation with species such as Rhizostoma, which have an apparent tendency to aggregate at the surface and thus allow semi-quantifiable estimates of abundance to be made. Such simplistic data might appear of limited use, and it might be argued that there are more efficient and accurate means of obtaining distribution data for open-water jellyfish. However, given the paucity of information on these common yet elusive species, such insights are invaluable. For example, our observations of Cyanea within the northern sections of the survey area could indicate niche-partitioning in the Irish Sea, as suggested by Russell (1970), whereas Chrysaora was found throughout the study area, suggesting less specific habitat preferences.

To conclude, we tested the suitability of direct visual counts from aircraft for the detection and estimation of jellyfish aggregations on a broad geographical scale. The results were mixed, the primary limitation being the inability to gather comparable, semi-quantifiable data on relative abundance between species. Nonetheless, on a geographical basis, inter-specific comparisons were possible: Rhizostoma was found to form distinct coastal aggregations, with the other 2 species being more dispersed throughout inshore and opensea areas. No matter how rudimentary, this finding represents a major step forward in our understanding of jellyfish in this well-studied body of water, as it provided real-time data on an international scale that would have been almost impossible using more conventional ship-based methods. The most salient point, however, is its potential for initially finding and relaying the location of jellyfish aggregations to ship-based operations: this could avoid many expensive and logistically demanding hours at sea prior to investigation. As an observational tool, the direct visual approach described may be used in isolation or in conjunction with more advanced techniques such as the visual imaging of Graham et al. (2003a) or the emerging LIDAR system (Churnside et al. 2003). Ultimately, therefore, we believe that this approach may provide an invaluable tool in future studies of jellyfish aggregations within our coastal seas, and facilitate investigations of previously elusive species, of which we know little more than their name.

Acknowledgements. Major funding was provided by a grant to G. Hays and J. Davenport from the INTERREG IIIA programme, part of the European Regional Development Fund. Further funding for aerial surveys was provided by the Countryside Council for Wales Species Challenge Fund. We thank everyone who assisted with aerial surveys and beach validations and especially V., S. and C. Rooney, J. and R. Hurley, K. McCormack, E. Lee, M. Doyle, D. Jones, K. Williamson and I. Kruszona; T. Stringell from the Countryside Council for Wales for guidance on aerial surveys; M. Wilson from University College Cork for assistance with interpretation and presentation of data.

\section{LITERATURE CITED}

Ancrenaz M, Gimenez O, Ambu L, Ancrenaz K and 6 others (2005) Aerial surveys give new estimates for orangutangs in Sabah, Malaysia. PLoS Biol 3:e3

Arai MN (2005) Predation on pelagic coelenterates: a review. J Mar Biol Assoc UK 85:523-536

Axiak VI, Galea C, Schmembri PJ (1991) Coastal aggregations of the jellyfish Pelagia noctiluca (Scyphozoa) in the Maltese coastal waters during 1980-1986. In: UNEP Proc II Workshop on Jellyfish in the Mediterranean Sea (Trieste, 2-5 September 1987). Map Tech Rep Ser 47:128-132

Bengtson JL, Ferm LM, Harkonen TJ, Stewart BS (1990) Abundance of Antarctic fur seals in the South Shetland Islands, Antactica, during the 1986/1987 austral summer. In: Kerry KR, Hempel G (eds) Antarctic ecosystems. Ecological change and conservation. Springer-Verlag, Berlin, p 265-270

Bodkin JL, Udewitz MS (1999) An aerial survey method to estimate sea otter abundance. In: Garner GW, Armstrup 
SC, Laake JL, Manly BF, McDonald LL, Robertson DG (eds) Marine mammal survey and assessment methods. Balkema, Rotterdam, p 13-26

Boucher S, Crete M, Ouellet JP, Daiigle C, Lesage L (2004) Large-scale trophic interactions: white-tailed deer growth and forest understory. Ecoscience 11:286-295

Brierley AS, Axelsen BE, Buecher E, Sparks CAJ, Boyer H, Gibbons MJ (2001) Acoustic observations of jellyfish in the Namibian Benguela. Mar Ecol Prog Ser 210:55-66

Brierley AS, Axelsen BE, Boyer DC, Lynam CP and 5 others (2004) Single target detections of jellyfish. ICES J Mar Sci 61:383-393

Brierley AS, Boyer DC, Axelsen BE, Lynam CP, Sparks CAJ, Boyer HJ, Gibbons MJ (2005) Towards the acoustic estimation of jellyfish abundance. Mar Ecol Prog Ser 295: 105-111

Brodeur RD, Sugisaki H, Hunt GL Jr (2002) Increases in jellyfish biomass in the Bering Sea: implications for the ecosystem. Mar Ecol Prog Ser 233:89-103

Brown ED, Churnside JH, Collins RL, Veenstra T, Wilson JJ, Abnett K (2002) Remote sensing of capelin and other biological features in the North Pacific using lidar and video technology. ICES J Mar Sci 59:1120-1130

Buecher E, Sparks C, Brierley A, Boyer H, Gibbons M (2001) Biometry and size distribution of Chrysaora hysoscella (Cnidaria, Scyphozoa) and Aqueora aequorea (Cnidaria, Hydrozoa) off Namibia with some notes on their parasite Hyperia medusarum. J Plankton Res 23:1073-1080

Churnside JH, Wilson JJ (2001) Airborne lidar for fisheries application. Opt Eng 40:406-414

Churnside JH, Demer DA, Mahmoudi B (2003) A comparison of fish schools in the Gulf of Mexico. ICES J Mar Sci 60: $147-154$

Dennis C (2003) Close encounters of the jelly kind. Nature 426:12-15

Forcada J, Gazo M, Aguilar A, Gonzalvo J, Fernández-Contreras M (2004) Bottlenose dolphin abundance in the NW Mediterranean: addressing heterogeneity in distribution. Mar Ecol Prog Ser 275:275-287

Gilchrist HG \& Mallory ML (2005) Declines in abundance of the ivory gull (Pagophila eburnea) in Arctic Canada. Biol Conserv 121:303-309

Graham WM, Martin DL, Felder DL, Asper VL, Perry HM (2003a) Ecological and economic implications of a tropical jellyfish invader in the Gulf of Mexico. Biol Invasions 5: 53-69

Graham WM, Martin DL, Martin JC (2003b) In situ quantification and analysis of large jellyfish using a novel video profiler. Mar Ecol Prog Ser 254:129-140

Hamner WM, Madin LP, Allredge AL, Gilmer RW, Hamner PP (1975) Underwater observations of gelatinous zooplankton: sampling problems, feeding biology and behaviour. Limnol Oceanogr 20:907-917

Hay SJ, Mislop JRG, Shanks AM (1990) North Sea Scyphomedusae: summer distribution, estimated biomass and significance particularly for O-group gadiod fish. Neth J Sea Res 25:113-130

Hays GC, Houghton JDR, Doyle T, Davenport J (2003) Aircraft give a new view of jellyfish behaviour. Nature 426 : 383

Kideys AE (1994) Recent dramatic changes in the Black Sea ecosystem: the reason for the sharp decline in Turkish anchovy fisheries. J Mar Syst 5:171-181

Marsh H, De'Ath G, Gribble N \& Lane B (2005) Historical marine population estimates: triggers or targets for conservation? The dugong case study. Ecol Appl 15:481-492

Mills CE (1995) Medusae, siphonophores and ctenophores as planktivorous predators in changing global ecosystems. ICES J Mar Sci 52:575-581

Mills CE (2001) Jellyfish blooms: are populations increasing globally in response to changing ocean conditions. Hydrobiologia 451:55-68

Nagabhushanam AK (1959) Studies on the biology of the common gadoids in the Manx area, with special reference to their food and feeding habits. PhD thesis, University of Liverpool. (Cited after Russell FS 1970)

Naumenko EA (2002) The dynamics of prespawning capelin (Mallotus villosus socialis) off the West Kamchatka coast. ICES J Mar Sci 59:1006-1010

O'Connor BDS, McGrath D (1978) On the occurrence of the scyphozoan Rhizostoma octopus (L.) around the Irish coast in 1976. Ir Nat J 19:261-263

Plante M, Lowell K, Potvin F, Boots B, Fortin MJ (2004) Studying deer habitat on Anticosti Island, Quebec: relating animal occurrences and forest map information. Ecol Model 174:387-399

Purcell JE, Arai MN (2001) Interaction of pelagic cnidarians and ctenophores with fish: a review. Hydrobiol 451:27-44

Purcell JE, Brown ED, Stokesbury KDE, Haldorson LH, Shirley TC (2000) Aggregations of the jellyfish Aurelia labiata: abundance, distribution, association with age-0 walleye pollock, and behaviours promoting aggregation in Prince William Sound, Alaska, USA. Mar Ecol Prog Ser 195:145-158

Royer F, Fromentin JM, Gaspar P (2004) Association between bluefin tuna schools and oceanic features in the western Mediterranean. Mar Ecol Prog Ser 269:249-263

Rugh DJ, Mahoney BA, Litzky LK, Smith B (2002) Aerial surveys of beluga in Cook Inlet, Alaska, June 2002. National Marine Mammal Laboratory, NMFS, NOAA, Seattle, WA Russell FS (1970) The Medusae of the British Isles. Vol II. Cambridge University Press, Cambridge

Scheel D, Hough KR (1997) Salmon fry predation by seabirds near an Alaskan hatchery. Mar Ecol Prog Ser 150:35-48

Shiganova TA (1998) Invasion of the Black Sea by the ctenophore Mnemiopsis leidyi and recent changes in pelagic community structure. Fish Oceanogr 7:305-3100

Shiganova TA, Bulgakova YV (2000) Effects of gelatinous plankton on Black Sea and Sea of Azov fish and their food resources. ICES J Mar Sci 57:641-648

Sonntag RP, Benke H, Hiby AR, Lick R, Adelung D (1999) Identification of the first harbour porpoise (Phocoena phocoena) calving ground in the North Sea. J Sea Res 41: 225-232

Sparks C, Buecher E, Brierley AS, Axelsen BE, Boyer H, Gibbons MJ (2001) Observations on the distribution and relative abundance of the scyphomedusan Chrysaora hysoscella (Linné, 1766) and the hydrozoan Aequorea aequorea (Forskål, 1775) in the northern Benguela ecosystem. Hydrobiologia 451:275-286.

Sparks C, Brierley AS, Buecher E, Boyer H, Axelsen BE, Gibbons MJ (2005) Submersible observations of the daytime distribution of Aequorea? forskalea off the west coast of southern Africa. J Mar Biol Assoc UK 85:519-522

Thompson PM, Van Parijs S, Kovacs KT (2001) Local declines in abundance of harbour seals: implications for the designation and monitoring of protected areas. J Appl Ecol 38: $117-125$

Submitted: June 27, 2005; Accepted: October 12, 2005

Proofs received from author(s): April 25, 2006 